closure technique. Histologically, it was proved in these patients that the cancer affected only the external layer of the aortic wall.

CT was a feasible means of judging whether malignant tumor had invaded the aorta by observing the motion of the tumors along the aortic wall. This method could be used for either purpose-to discriminate T4 tumors from others as a contraindication for resection or to devise a strategy for concomitant resection of the aorta. Provided an invaded portion of the aorta, which is in contact with the immobile surface of a tumor, has been revealed clearly before the operation, a circulatory bypass and prosthesis required for resection and replacement of the wall can be arranged appropriately. In our seven cases, we took advantage of the new imaging modality in this way.

In our series, one tumor in contact with the distal arch was erroneously judged to be invasive. The most likely reason for this misdiagnosis was that the tumor was located on the distal arch near the pulmonary hilus and thus showed barely detectable upward and downward motion during breathing. For the same reason, a noninvasive tumor located on the diaphragm near the pulmonary ligament might be judged invasive by mistake. To avoid such misdiagnoses of pulmonary tumors located on the distal arch or diaphragm, the investigator should use the heartbeat mode as well as the breathing mode for more accurate evaluation, rather than using the breathing mode alone.
It is still difficult to discriminate between invasion and fibrous adhesion. We believe that cine CT should reveal malignant adhesion distinctly, because such invasion shows tougher attachment with less mobility than simple fibrous adhesion. A study including more patients will be required to address this issue.

\section{REFERENCES}

1. Bateman TM, Gray RJ, Whiting JS, Matloff JM, Berman DS, Forrester JS. Cine computed tomographic evaluation of aortocoronary bypass graft patency. J Am Coll Cardiol 1986;8: 693-8.

2. Bateman TM, Gray RJ, Whiting JS, et al. Prospective evaluation of ultrafast cardiac computed tomography for determination of coronary bypass graft. Circulation 1987; 75:1018-24.

3. Froissart M, Archambaud F, Hernigou A, et al. Measurement of global and separate renal blood flow using cine-computed tomography. J Radiol 1994;75:715-21.

4. Garrett JS, Lanzer P, Jaschke W, et al. Measurement of cardiac output by cine computed tomography. Am J Cardiol 1985;56:657-61.

5. Mathru M, Wolfkiel CJ, Jelnin V, et al. Measurement of right ventricular volume in human explanted hearts using ultrafast cine computed tomography. Chest 1994;105:585-8.

\title{
APROTININ USE IN PATIENTS WITH DIALYSIS-DEPENDENT RENAL FAILURE UNDERGOING CARDIAC OPERATIONS
}

John H. Lemmer, Jr., MD, Mark T. Metzdorff, MD, Albert H. Krause, MD, J. Edward Okies, MD, Thomas A. Molloy, MD, Jonathan G. Hill, MD, William B. Long, MD, Thomas R. Winkler, MD, and U. Scott Page, MD, Portland, Ore.

It is occasionally necessary for patients with chronic renal failure (CRF) who are dependent on dialysis to undergo cardiac operations. Patients with CRF are at increased risk for excessive bleeding and often require substantial blood product transfusions in conjunction with

From Legacy Good Samaritan Hospital, Portland, Ore.

Consulting statistician: Andrea Nadel, $\mathrm{PhD}$, Bayer Corporation, Pharmaceutical Division, West Haven, Conn.

Received for publication Nov. 22, 1995; accepted for publication Jan. 5, 1996.

Address for reprints: John H. Lemmer, Jr., MD, Northwest Surgical Associates, 2226 NW Pettygrove, Portland, OR 97210.

J Thorac Cardiovase Surg 1996;112:192-4

Copyright (c) 1996 by Mosby-Year Book, Inc.

$0022-5223 / 96 \$ 5.00+0 \quad \mathbf{1 2 / 5 4 / 7 1 6 2 5}$ the surgical procedure..$^{1-3}$ Aprotinin, an inhibitor of fibrinolysis with salutary effects on platelet function, decreases bleeding and blood product transfusion requirements when administered during cardiac operations, but published results of aprotinin use in patients with CRF is limited. ${ }^{4-6}$ In this report we describe seven patients dependent on dialysis who received aprotinin during cardiac procedures and compare them with nine patients with CRF who did not.

Methods. Between February 1993 and May 1995, 16 patients with dialysis-dependent CRF underwent cardiac operations done by our group. The patients required dialysis (peritoneal dialysis or hemodialysis) for CRF of various types. All patients underwent dialysis within the 24-hour period before the operation. Standard blood conservation techniques were used in both groups, including tolerance of moderate to severe anemia, use of an intraoperative cell scavenging device, and postoperative 
Table I. Patient characteristics

\begin{tabular}{lcc}
\hline & $\begin{array}{c}\text { Aprotinin } \\
\text { group } \\
(n=7)\end{array}$ & $\begin{array}{c}\text { Control } \\
\text { group } \\
(n=9)\end{array}$ \\
\hline Age $(\mathrm{yr})$ & $60 \pm 15$ & $60 \pm 13$ \\
Weight $(\mathrm{kg})$ & $67 \pm 8$ & $70 \pm 15$ \\
Male gender & $4 / 7$ & $5 / 9$ \\
CABG procedures & $5 / 7$ & $7 / 9$ \\
Valve procedures & $2 / 7$ & $1 / 9$ \\
Valve and CABG & $0 / 7$ & $1 / 9$ \\
Use of intraoperative hemofiltration & $4 / 7$ & $5 / 7$
\end{tabular}

Numeric values are mean \pm standard deviation. There were no significant differences between the two groups. CABG, Coronary artery bypass graft.

autotransfusion of shed mediastinal blood. The control group patients were not matched; aprotinin administration was open label and not randomized. Patient characteristics are summarized in Table I.

In the aprotinin-treated group, four of the patients had elective operations and three urgent operations because of unstable angina symptoms. Two patients were receiving continuous intravenous heparin when the operation was begun and two patients had received aspirin within 24 hours of the operation. In the control group none was treated with aprotinin, one received intraoperative aminocaproic acid, and one procedure was performed with heparin-coated extracorporeal circulation (ECC) tubing and oxygenator. Five of these operations were performed on an urgent basis and four were elective. One patient was receiving intravenous heparin just before the operation and one patient had received aspirin within 3 days of the operation. One operation was a second procedure.

Aprotinin (Bayer Corporation, Pharmaceutical Division, West Haven, Conn.) was administered as follows: $280 \mathrm{mg}$ loading dose over 20 minutes before beginning $\mathrm{ECC}, 280 \mathrm{mg}$ added to the ECC prime solution, and a continuous infusion of $70 \mathrm{mg} / \mathrm{hr}$ during the operation. Standard anesthetic technique was used and the ECC circuit used a centrifugal pump and membrane oxygenator. Diastolic arrest of the heart was induced with cold blood hyperkalemic $(20 \mathrm{mEq} / \mathrm{L})$ cardioplegic solution, and maintenance doses of low-potassium $(4 \mathrm{mEq} / \mathrm{L})$ cardioplegic solution were administered during the crossclamp period. Moderate systemic hypothermia $\left(28^{\circ}\right.$ to $32^{\circ} \mathrm{C}$ ) was used in all patients. In control patients anticoagulation for $\mathrm{ECC}$ was achieved by standard techniques to maintain the kaolin activated clotting time (ACT) above 480 seconds during the period of ECC. For the patient in whom heparin-bonded circuitry was used, the ACT level was maintained at 200 to 300 seconds. Anticoagulation for the aprotinin-treated group was accomplished by use of an $A C T$-directed fixed-dose heparin regimen. For this purpose, the patient received a loading dose of 450 units of heparin per kilogram to achieve a prebypass kaolin ACT of more than 600 seconds. Additionally, 10,000 units of heparin was added to the ECC circuit prime solution and the patient received 100 units of heparin per kilogram every 60 minutes during bypass (irrespective of the most
Table II. Chest tube drainage, transfusions, and complications

\begin{tabular}{lccc}
\hline & $\begin{array}{c}\text { Aprotinin } \\
(n=7)\end{array}$ & $\begin{array}{c}\text { Control } \\
(n=9)\end{array}$ & $\begin{array}{c}p \\
\text { Value }\end{array}$ \\
\hline $\begin{array}{l}\text { Twelve-hour drainage (ml) } \\
\text { Total drainage (ml) }\end{array}$ & $\begin{array}{c}315 \pm 103 \\
486 \pm 159\end{array}$ & $\begin{array}{c}1096 \pm 561 \\
1271 \pm 710\end{array}$ & 0.001 \\
$\begin{array}{l}\text { Mean No. of total blood } \\
\text { product exposures per }\end{array}$ & $3.7 \pm 4$ & $29.0 \pm 32$ & 0.040 \\
$\quad$ patient & & & \\
$\begin{array}{l}\text { Mean No. of RBC units } \\
\text { transfused }\end{array}$ & $2.0 \pm 2$ & $6.0 \pm 7$ & 0.315 \\
$\begin{array}{l}\text { Mean No. of platelet units } \\
\text { transfused }\end{array}$ & $1.7 \pm 3$ & $14.6 \pm 16$ & 0.011 \\
$\begin{array}{l}\text { Mean No. of plasma units } \\
\text { transfused }\end{array}$ & 0 & $4.8 \pm 7$ & 0.011 \\
$\begin{array}{l}\text { Mean No. of cryoprecipi- } \\
\quad \text { tate units transfused }\end{array}$ & 0 & $3.6 \pm 7$ & 0.475 \\
$\begin{array}{l}\text { Reoperations for bleeding } \\
\text { Deaths }\end{array}$ & $0 / 7$ & $2 / 9$ & $\mathrm{NC}$ \\
$\begin{array}{l}\text { Preop. hematocrit value } \\
\quad \%)\end{array}$ & $0 / 7$ & $1 / 9$ & $\mathrm{NC}$ \\
$\begin{array}{l}\text { Postop. hematocrit value } \\
\quad \%)\end{array}$ & 33.1 & 35.4 & $\mathrm{NC}$ \\
$\quad$
\end{tabular}

$R B C$, Red blood cell; $N C$, not calculated.

recent ACT determination). The protamine dose was 0.75 $\mathrm{mg} / 100$ total heparin units administered.

Blood products were transfused at the discretion of the operating surgeon and no specific criteria were used. In general, however, red blood cells were transfused for a hematocrit level of less than $18 \%$ during ECC and $21 \%$ after the operation, with additional blood product transfusions given when clinically indicated. All $p$ values were computed by means of Fisher's exact test. In Table II, a median test was applied; all variables were first categorized as to whether the value was above the sample mean.

Results. Characteristics of the patients in the two groups were similar (Table I). Table II summarizes the volumes of chest tube drainage and blood product transfusion requirements. Chest tube drainage in the first 12 hours and total chest tube drainage volumes were smaller in the patients treated with aprotinin, although the latter difference did not reach statistical significance. Substantially fewer total blood product transfusions were required by the patients who received aprotinin. The mean number of red blood cells transfused to them was one third the number transfused to the control patients, but this difference did not reach statistical significance, presumably because of the small number of patients compared.

Two control group patients required exploration because of excessive postoperative bleeding as compared with none of the patients receiving aprotinin. Both patients had diffuse bleeding. No strokes or myocardial infarctions (assessed by electrocardiograms and postoperative creatine kinase MB levels) occurred in any of the patients. One 72-year-old patient from the control group died of coagulopathy (necessitating exploration for bleed- 
ing) and cardiac and liver failure after a second coronary bypass graft procedure. Severe gastrointestinal hemorrhage developed on the fifth postoperative day in one patient treated with aprotinin, necessitating transfusions of red blood cells ( 2 units) and platelets ( 6 units). These transfusions were included in the calculations of the means shown in Table II. Telephone follow-up (mean 15 months after the operation) of the aprotinin-treated group found five alive and angina free (two on kidney transplant waiting lists); one 85 -year-old patient had died of unknown causes and one 58-year-old patient had died of "atherosclerosis" 4 and 14 months, respectively, after their operations.

Comment. Abnormalities of the hemostatic system in patients with CRF are widely recognized and appear to be multifactorial in origin. ${ }^{7}$ Multiple reports indicate that cardiac operations may be performed successfully in patients with CRF, although complication rates are higher and the overall mortality is estimated to be $9 \% .{ }^{1}$ In publications that provide this information, the mean number of blood product transfusions per patient with CRF undergoing cardiac procedures ranged from 8 to 20 units per patient. ${ }^{1-3}$ This is considerably greater than the average of 4 units per patient who received aprotinin during the operations as described in this report.

The choice of aprotinin dose regimen for our patients was based on reported results available at the time of their operations. Subsequently, evidence has emerged indicating efficacy of smaller aprotinin doses. ${ }^{6}$ In patients with normal renal function, aprotinin is excreted by the kidneys. In patients with CRF the route of elimination is not known, although some proportion may be cleared by dialysis. Because early renal aprotinin elimination cannot occur in patients with CRF, a lower dose should likely be effective in these patients (at a lower cost).

This is a retrospective report of two small groups of patients with dialysis-dependent CRF who were operated on by one group of surgeons, and it is subject to limitations of such reports. The patients were not randomized with regard to aprotinin treatment, blinded conditions were not used, and strict transfusion criteria were not applied. It is therefore an observational report rather than an investigation rigorously comparing two treatment modalities. Nevertheless, in our experience with seven patients with dialysis-dependent CRF undergoing cardiac operations, high-dose aprotinin administration was associated with reductions in bleeding and homologous blood product transfusions, and no complications related to the use of the drug were identified. For these reasons, it is our current recommendation that aprotinin be used in this group of patients who are at high risk for perioperative hemorrhagic problems. On the basis of recently published results, the use of a smaller aprotinin dose should be considered.

\section{REFERENCES}

1. Ko W, Kreiger KH, Isom OW. Cardiopulmonary bypass procedure in dialysis patients. Ann Thorac Surg 1993;55:67784.

2. Owen CH, Cummings RG, Sell TL, et al. Coronary artery bypass grafting in patients with dialysis-dependent renal failure. Ann Thorac Surg 1994;58:1729-33.

3. Blakeman BP, Sullivan HJ, Foy BK, Sobotka PA, Pifarré R. Internal mammary artery revascularization in the patient on long-term renal dialysis. Ann Thorac Surg 1990;50:776-8.

4. Lemmer JH Jr, Stanford W, Bonney SL, et al. Aprotinin for coronary bypass operations: efficacy, safety, and influence on early saphenous vein graft patency-a multi-center, randomized, double-blind, placebo-controlled study. J Thorac Cardiovasc Surg 1994;107:543-53.

5. Levy JH, Pifarré R, Schaff HV, et al. A multi-center, doubleblind, placebo-controlled trial of aprotinin for reducing blood loss and the requirements for donor-blood transfusion in patients undergoing repeat coronary artery bypass grafting. Circulation 1995;92:2236-44.

6. Ueyama $K$, Ohashi $H$, Tsutsumi $Y$, et al. A case report of coronary artery bypass grafting surgery with aprotinin in a patient undergoing chronic hemodialysis. Jpn J Thorac Surg 1994;47:288-90.

7. Eberst ME, Berkowitz LR. Hemostasis in renal disease: pathophysiology and management. Am J Med 1994;96:168-79. 